\title{
Freshening rather than warming drives trematode transmission from periwinkles to mussels
}

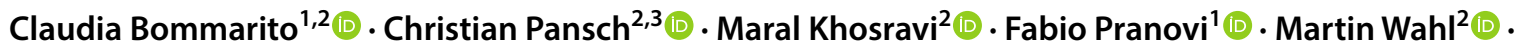 \\ David W. Thieltges ${ }^{4}(\mathbb{0}$
}

Received: 12 October 2019 / Accepted: 27 January 2020 / Published online: 3 March 2020

(C) The Author(s) 2020

\begin{abstract}
In the Western Baltic Sea, climate change is happening at much faster rate than in most other seas and organisms are additionally exposed to a steep and variable salinity gradient. Climate change has previously been shown to affect parasite transmission in other marine ecosystems, yet little is known about potential effects of warming and desalination on parasite-host interactions. In laboratory experiments, we determined the combined effects of projected seawater warming and freshening on the emergence, activity, survival, and infectivity of cercariae (free-swimming infectious stage) of the trematode Himasthla elongata (Mehlis 1831), shed from its first intermediate host, the periwinkle Littorina littorea (Linnaeus 1758), in the Baltic Sea. We also assessed the susceptibility of the second intermediate host, the mussel Mytilus edulis Linnaeus, 1758, to cercarial infections. Generally, salinity was the main driver, particularly of cercarial activity, infectivity, and mussel susceptibility to infection. At the lowest salinity (13), cercariae were 50\% less active compared to the highest salinity (19). Infection success and host susceptibility followed a similar pattern, with $47 \%$ and $43 \%$ less metacercariae (encysted stage) present at salinity 13 than at salinity 19, respectively. In contrast, effects of simulated warming were found only for cercarial survival, with cercarial longevity being higher at 19 than at $23{ }^{\circ} \mathrm{C}$. No significant interactions between temperature and salinity were found. In contrast to the literature, the results suggest that a climate change-driven freshening (partly also warming) may lead to a general decline of marine trematodes, with possible beneficial effects for the involved hosts.
\end{abstract}

Responsible Editor: P. A. Ramey-Balci.

Reviewed by T. González, C. Macleod, and undisclosed experts.

Electronic supplementary material The online version of this article (https://doi.org/10.1007/s00227-020-3657-3) contains supplementary material, which is available to authorized users.

Claudia Bommarito

claudia.bommarito@unive.it; cbommarito@geomar.de

1 Department of Environmental Sciences, Informatics and Statistics, University Ca' Foscari of Venice, 30172 Venice, Italy

2 Department of Marine Ecology, GEOMAR Helmholtz Centre for Ocean Research Kiel, 24105 Kiel, Germany

3 Environmental and Marine Biology, Åbo Akademi University, Artillerigatan 6, 20520 Abo, Finland

4 Department of Coastal Systems, NIOZ Royal Netherlands Institute for Sea Research, Utrecht University, P.O. Box 59, 1790, AB, Den Burg Texel, The Netherlands

\section{Introduction}

Climate change is expected to affect a wide range of interactions among marine organisms, including interactions between parasites and their hosts (Poulin and Mouritsen 2006; Marcogliese 2008). In general, parasites are widespread in aquatic environments, and often interact with various ecosystem stressors, both at the population and the community level of the hosts they infect (Sures 2008; Nachev and Sures 2015; Vidal-Martínez and Wunderlich 2017). At the same time, parasites have been shown to have profound impacts on aquatic ecosystems by numerous direct and indirect effects on host populations and communities (Mouritsen and Poulin 2009; Sures et al. 2017). For instance, as reported by Wood et al. (2007), grazing activity of infected Littorina sp. on macroalgae decreased by $40 \%$ compared to non-infected individuals, indirectly causing changes in community structure of ephemeral algae. Given the important ecological roles of parasitism, an understanding of the links between parasite infection levels in hosts and changing environmental conditions is crucial to identify the effects 
of climate change on parasites and their hosts in marine ecosystems.

Many parasites have complex life cycles, often involving several sequential hosts. The free-living transmission stages in between hosts are known to be particularly sensitive to abiotic factors (Pietrock and Marcogliese 2003; Koprivnikar et al. 2010). Of those factors, temperature has been studied most intensively (Marcogliese 2016), in particular in cercarial life cycle stages of trematodes. Cercarial stages emerge from a first intermediate gastropod host and penetrate the second intermediate host tissue, in which they transform into the following life cycle stage (metacercariae), awaiting ingestion by the final host (marine bird). Diverse experimental studies have demonstrated positive correlations between increasing seawater temperature and cercarial emergence and infectivity (Thieltges and Rick 2006; Koprivnikar and Poulin 2009; Studer and Poulin 2013). Both emergence and infectivity occasionally decrease after a certain threshold depending on the trematode species studied (McCarthy 1999; Thieltges and Rick 2006; Koprivnikar and Poulin 2009). Temperature can also affect transmission to the next host, by direct effects on the infectivity of free-living cercariae (Pechenik and Fried 1995; Studer et al. 2010) or changes in the susceptibility of the second intermediate host to parasite infection (Laverty et al. 2017).

Considering that global change is a complex of different interacting changes, abiotic factors, such as salinity or $\mathrm{pH}$ changes, other than temperature may further modify the emergence, survival, and infectivity of free-living stages of trematodes, as well as the resistance of their hosts (Zander 1998; Mouritsen 2002; Pietrock and Marcogliese 2003; Leiva et al. 2019). Moreover, previous comparative analyses (Morley 2011; Morley and Lewis 2013; Marcogliese 2016) confirmed a large range of thermal tolerance beyond optimum temperatures for cercarial emergence and survival. These findings suggest that temperature may not represent the most relevant variable for parasitism as thought previously. In coastal marine environments, salinity can play a prominent role in parasite transmission and previous studies found decreases in cercarial emergence and infectivity at reduced salinities (Lei and Poulin 2011). Salinity may interact with temperature as indicated by multi-factorial experiments. For example, Koprivnikar et al. (2010) found mean survival of cercarial stages of Acanthoparyphium spinulosum compromised at 35 and 40 at $25{ }^{\circ} \mathrm{C}$ but not at $20{ }^{\circ} \mathrm{C}$. However, many of these multi-factorial experiments focused on single phases of cercarial life cycles only, not including other possibly relevant transmission and developmental steps.

In the Baltic Sea, salinity gradients represent one of the major drivers of benthic community composition (Ojaveer et al. 2010; Jasper et al. 2011; Vuorinen et al. 2015). The inflow of high-saline bottom water from the North Sea and the outflow of shallow low-saline water, mostly from riverrunoff and precipitation (Müller et al. 2016), create a strong Baltic-wide salinity gradient from about 30 (Skagerrak and Kattegat region in the west, southwest) down to 3 in the northeast area of the Gulf of Bothnia. The steepest salinity gradient is found in the South-Western Baltic Sea (i.e., eastern coast of Denmark and northeastern German coast), where salinity drops from 20 to 8 over $400 \mathrm{~km}$ (Bonsdorff 2006). Due to this strong gradient of osmotic stress its landlocked nature, intense anthropogenic pressures, and its strong environmental fluctuations, the Baltic Sea represents a hot spot to study climate change effects. Regional impacts are accompanied by global changes such as warming and ocean acidification. The Baltic Sea was indeed identified as the fastest-warming sea worldwide, and one of the fastest under increased nutrient load and oxygen depletion in bottom waters (with the Black Sea and the East China Sea; Reusch et al. 2018).

In this study, we investigated the single and combined effects of seawater warming and freshening on different life stages of the trematode Himasthla elongata, one of the dominant trematode species in the Western Baltic Sea (Lauckner 1984a, b). This parasite uses marine snails (Littorina littorea) as first intermediate host and blue mussels (Mytilus edulis), and other bivalve species, as second intermediate host. Coastal birds feeding on mussels represent the final host (Lauckner 1984a, b). Himasthla sp. cercariae normally survive up to a maximum of 2 days, with $100 \%$ survival rate within $24 \mathrm{~h}$ (de Montaudouin et al. 2016). Cercariae of $\mathrm{H}$. elongata at $20^{\circ} \mathrm{C}$ were found to maintain infectivity for around $20 \mathrm{~h}$ (Greve 1997). We assessed the different transmission steps from the first to the second intermediate host (Fig. 1): (i) cercarial emergence from periwinkles, (ii) cercarial activity and survival after emergence, (iii) cercarial infectivity in mussels, and (iv) susceptibility of mussels to cercarial infection. For (iii), cercariae were treated but not the mussels, whereas for (iv), mussels were treated but not the cercariae. With this study, we contribute to a better understanding of the effects of expected warming and freshening on parasite transmission success in a Baltic Sea host-parasite system.

\section{Methods}

\section{Parasite and host collection}

Approximately 500 periwinkles (L. littorea) were haphazardly collected by hand at Årøsund, Denmark $\left(55.25^{\circ} \mathrm{N}\right.$, $9.70^{\circ} \mathrm{E}$ ) in August 2017, and transported to the GEOMAR laboratory in Kiel, Germany. Here, periwinkles were kept together in plastic containers of $25 \mathrm{~L}$ filled with seawater at 19 and $16^{\circ} \mathrm{C}$ (i.e., the conditions at the site and time of 


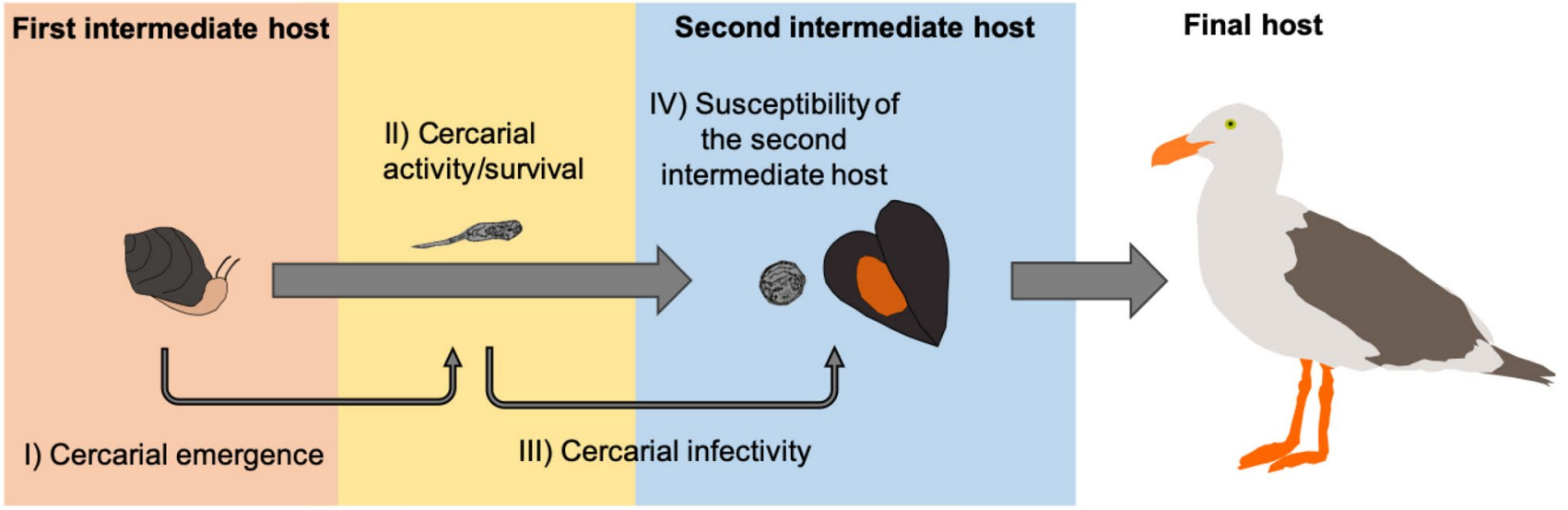

Fig. 1 Life cycle of the trematode Himasthla elongata and transmission steps investigated in this study: Exp. I: cercarial emergence from the first intermediate host, the periwinkle Littorina littorea; Exp. II: cercarial activity/survival; Exp. III: cercarial infectivity; Exp. IV: susceptibility of the second intermediate host, the blue mussel Mytilus edulis, to cercariae infection. Different colours represent the different phases of the life cycle on which we focused: the first host/cercarial phase (red), the cercarial free-living phase (yellow), and the phase within the metacercarial stage in the second intermediate host (blue)

and the expected increment by $2100\left(+4{ }^{\circ} \mathrm{C}\right.$; IPCC Report 2019). Salinity levels applied were 13,16 , and 19 . Following predictions for the Baltic Sea, salinity is expected to drop due to increasing precipitation rates and freshwater runoff (Vuorinen et al. 2015; Johnson et al. 2018). We, thus, chose two severity levels of desalination, i.e., reduction by 3 and 6 , respectively, from 19 which is the average salinity of Årøsund, the site where L. littorea was collected. Furthermore, the activity of L. littorea was shown to considerably decrease at salinities below 13.5 (Rosenberg and Rosenberg 1972).

The experiments were conducted in six temperaturecontrolled water baths $(50 \times 50 \times 50 \mathrm{~cm})$ located in a single climate chamber $\left(16^{\circ} \mathrm{C}\right)$. Cercarial motility and survival was assessed in a different room, using six smaller temperature-controlled water baths $(8 \mathrm{~L})$. Three of the six water baths were set at 23 and three at $19{ }^{\circ} \mathrm{C}$, and each water bath included all salinity levels. There were (i) five independent containers (one periwinkle per container) per salinity level per water bath for the cercarial emergence phase, (ii) one 96 -well plate ( 15 cercariae, one cercaria per well) per salinity level per water bath for the functional activity/survival phase, and (iii) four independent containers (one mussel per container) per salinity level per water bath for the infection success and susceptibility phases. For each salinity level, filtered Kiel Fjord seawater was used and either marine salt (Seequasal) or deionized water was added, until the desired salinity was reached. In each experiment, temperature and salinity were measured with a digital salinity meter (ProfiLine, Cond 3110, WTW), within the experimental jars every other day. 


\section{Exp. I cercarial emergence from periwinkles}

Cercarial emergence was assessed by counting all cercariae that emerged from single periwinkles exposed to the different treatments. Infected periwinkles (20-25 mm length) were haphazardly assigned to the different treatment combinations. Periwinkles were placed individually into $250 \mathrm{~mL}$ glass jars filled with seawater at the different salinities. Water at the respective salinity conditions was prepared by adding salt (Seequasal) or DI water as necessary. After individually adding the snails, each jar was tightly closed with a lid preventing evaporation and provided with a small hole to allow oxygenation through a tube (from air pumps). Salinity and temperature were checked every other day before the water change, and only minor salinity increments were registered $(+0.2-0.3)$. Five jars per salinity treatment were placed into each waterbath (three baths for each temperature level $\mathrm{x}$ five periwinkles/ jars for each salinity level, i.e., 15 periwinkles in total per treatment combination), to acclimate periwinkles to the respective temperature and salinity levels. Periwinkles were fed daily ad libitum with $U$. lactuca and the water was exchanged every second day. Acclimation to the different temperatures and salinities lasted for 1 week, increasing/decreasing temperature and salinity by $1{ }^{\circ} \mathrm{C}$ and 1 psu per day, respectively.

To measure cercarial emergence, periwinkles were individually transferred from the jars into $50 \mathrm{~mL}$ Plexiglas beakers (Omnilab, ESM Fig. S2a), 1 day after the 7-day acclimation (measurement 1), 1 week after the start of exposure to the treatments (measurement 2), and 2 weeks after the start of exposure to the treatments (measurement 3 ), representing three sequential measurements for each individual periwinkle. Each incubation lasted $8 \mathrm{~h}$. Each beaker was filled with $40 \mathrm{~mL}$ of seawater of the respective salinity and small amounts of $U$. lactuca were added. The beakers were covered with a net and incubated for $8 \mathrm{~h}$ in the same water baths from which the periwinkles originated (ESM Fig. S2b) At the end of the incubation period, the periwinkles were individually placed back into their $250 \mathrm{~mL}$ glass jars at treatment conditions, while the water from each beaker was transferred into $50 \mathrm{~mL}$ Falcon tubes. In addition, the beakers were immediately washed with $5 \mathrm{~mL}$ ethanol (99\%), and the solution was also added to the Falcon tube to ensure the collection of all cercariae and their preservation for later counting. Samples were centrifuged for five minutes at $800 \mathrm{~g}$, excess water was discarded, and cercariae at the bottom were poured into a petri dish for counting under a stereomicroscope (Nikon, SMZ1000). Periwinkles that did not shed any cercariae over all the three incubations were excluded from the analysis.

\section{Exp. II cercarial activity and survival}

Infected periwinkles were acclimated for 3 weeks under the different treatments ( $n=10$ individuals per treatment) and incubated as described above for $4 \mathrm{~h}$ to allow for cercarial release. At the start of the experiment, approximately 45 cercariae per treatment, obtained from the pooled cercariae released within four hours from the ten snails per treatment, were added individually to wells of three 96 -well plates ( $n=15$ wells into three replicate 96 -well plates per salinity; 45 wells in total). The amount of water (of the respective salinity levels of 13,16 , and 19) in each well was around $0.25 \mathrm{~mL}$. The 96-well plates were tightly closed with the respective manufacturer's lids throughout the $45 \mathrm{~h}$ period preventing evaporation, except when cercariae were examined for activity and survival. The 96-well plates were then exposed to the different temperature treatments placing them in the six thermobaths (three thermobaths for each temperature level $\mathrm{x}$ one 96-well plate for each salinity level= three 96-well plates per treatment combination). Activity and survival were then assessed by visual assessment under a stereomicroscope after 4, 6, 9, 18, 27, and $45 \mathrm{~h}$. Cercariae were considered fully active when they were constantly swirling around (category: fully active). When cercariae were laying at the bottom of a well and not reacting after physical stimuli (through pipette's tip), these were considered dead (category: dead), when still reacting, even if slowly, these were still considered alive (category: alive). This last category included "fully active". Wells that accidentally received more than just one cercaria during the inoculation were excluded from the analysis.

\section{Exp. III cercarial infectivity in mussels}

The infectivity of $H$. elongata cercariae was investigated by counting metacercariae in $M$. edulis, after a standardized exposure to cercariae acclimated at different temperatures and salinities. Infected periwinkles were acclimated to the treatments for 4 weeks prior to the infection success assays. Mussels were collected 2 days prior to the start of the assays, kept in ambient salinity and temperature conditions and fed with Rhodomonas salina. A total of 72 mussels ( $n=12$ for each treatment combination) of $40-50 \mathrm{~mm}$ shell length, kept at $19 \mathrm{psu}$ and $16{ }^{\circ} \mathrm{C}$, were individually placed in $50 \mathrm{~mL}$ beakers at the respective temperatures and salinities, and exposed to a standardized number of cercariae released from the all periwinkles from the different treatment combinations. In each waterbath, four beakers per salinity combination were placed, i.e., a total of 12 beakers per bath. To obtain cercarial stages for the infection assays, periwinkles were individually placed in petri dishes at the different salinities and incubated for four hours under constant light (see above). After release, 
all cercariae (4-5 $\mathrm{h}$ old) of a given treatment combination were collected mixing the water from the different petri dishes into one single container, counted under the stereomicroscope and immediately added to the mussels. This accounted for genotypic and phenotypic variation among cercariae. Each of the 12 mussels of a given treatment combination was inoculated with $22\left(13-19^{\circ} \mathrm{C}, 16-19{ }^{\circ} \mathrm{C}\right.$ and $\left.19-23{ }^{\circ} \mathrm{C}\right)$, or $23\left(19-19{ }^{\circ} \mathrm{C}\right)$ cercariae, except for the $16-23{ }^{\circ} \mathrm{C}$ treatment, in which only five mussels where infected with 20 cercariae each due to the low number of cercariae obtained from such pre-treated periwinkles. The $13-23{ }^{\circ} \mathrm{C}$ treatment was excluded from the analyses due to extremely low numbers of cercariae released under this particular treatment combination. The beakers with mussels were then returned to the water baths at the treatment temperature and incubated for $24 \mathrm{~h}$. This incubation period was chosen to ensure cercarial encystation (de Montaudouin et al. 2016), but to also limit possible metabolic stress for the host, that could have affected the experiment. After the incubation, each mussel was collected and dissected, and $H$. elongata metacercariae were identified and counted under a stereomicroscope.

\section{Exp. IV susceptibility of acclimated mussels to cercarial infection}

The effects of temperature and salinity on the susceptibility of $M$. edulis to infection by $H$. elongata cercariae were assessed by acclimating mussels to the above-mentioned treatment combinations (salinity $\times$ temperature) for 1 week, before these were exposed to non-acclimated cercariae. In this experiment, cercariae did not receive any temperature/salinity treatment and only the mussels did (after acclimation), to specifically investigate a putative shift in susceptibility under the treatments by the second intermediate host. We assumed acclimation effects to be stronger in the (acclimated) hosts and less likely on the very shortterm basis in the added (non-acclimated) cercariae. However, some potential confounding factors by cercariae very quickly acclimatised cannot be fully excluded. Cercariae were obtained as described above from periwinkles collected 2 days earlier from the sampling site at Årøsund, Denmark. The exposure to cercariae of each mussel ( $n=12$ mussels per treatment) was realized as described for Exp. II, but this time, the number of cercariae added to individual mussels was $54\left(16-19{ }^{\circ} \mathrm{C}, 16-23{ }^{\circ} \mathrm{C}\right.$ and $\left.19-23{ }^{\circ} \mathrm{C}\right), 53\left(13-19{ }^{\circ} \mathrm{C}\right)$, and $56\left(19-19{ }^{\circ} \mathrm{C}\right)$. Beakers with mussels were incubated at the different treatments for $24 \mathrm{~h}$. Mussels were then dissected and the number of metacercariae in each mussel (squeezed between two glass plates) was counted under a stereomicroscope.

\section{Statistical analysis}

Prior to analysis, the normality of data distribution was tested through Shapiro-Wilk tests (Shapiro and Wilk, 1965) and residual plots were checked visually. Non-parametric Generalised Linear Mixed Models (GLMMs), using the packages $1 \mathrm{~m} 4$ and MASS, were then applied to cercarial emergence, infectivity, and mussel susceptibility. Residual extraction, the marginal $R^{2}$, and conditional $R^{2}$ were used to reveal individual identity and thermobath effect, using the function r.squared GLMM (package MuMIn; Nakagawa and Schielzeth 2013). Individual identity nested within thermobath was then used as random factor in all the steps analysed with GLMM. The Akaike Information Criterion (AIC) was used to select the best GLMM model, from models including all fixed factors and reduced models (without temperature or salinity as fixed factors). Two-way ANOVA was instead used for activity and survival. All statistical analyses were performed using the software R 3.5.0 (R Development Core Team 2018).

For cercarial emergence, a negative binomial GLMM, using the lme4 package, was used to test for the effects of temperature, salinity, and sampling time (fixed factors) on the number of $H$. elongata cercarie (Exp. I). Negative binomial structure was chosen due to high over-dispersion and presence of zeros in the data.

For cercarial activity/survival (Exp. II), the analysis applied was selected to link Exp II with Exp. III. For this purpose, we accounted of the differential slope of decreasing activity/survival during these $24 \mathrm{~h}$ by considering the integral over time (integrated area), which should correspond to the (changing) infection pressure that the mussels underwent in the infection experiments. The average proportion of "fully active" and "alive" cercariae present in one 96-well plate was considered as one replicate. Proportions were calculated through the 'survfit' function (package survminer). The integral areas of both $0-24 \mathrm{~h}$ and $0-45 \mathrm{~h}$ intervals were calculated using the mean proportions of the three 96-well plates to fit the curves. Curves of activity were fitted using geometric model (Power Low family), and the curves of survival using logistic power model (Sigmoidal models) (software: CurveExpert Professional 2.6.5). To test the effects, two separated two-factorial ANOVA were applied for each interval. Integrated motility and survival at $24 \mathrm{~h}$ and $45 \mathrm{~h}$ were the dependent variables, and temperature and salinity were the independent variables. Post hoc tests [Tukey honestly significant difference (HSD)] were performed following ANOVA.

Cercarial infectivity in M. edulis (Exp. III) was tested by a GLMM fitted with a Poisson structure with the number of metacercariae found in mussel tissue as dependent variable, and temperature and salinity were set as fixed factors. The same methodology as for infectivity was applied for 
susceptibility, however, here applying a GLMM fitted with a negative binomial structure.

Using the raw data, the effects of i) strong future freshening (salinity 13) in relation to present conditions (salinity 19) and ii) strong warming $\left(23^{\circ} \mathrm{C}\right)$ in relation to present condition $\left(19^{\circ} \mathrm{C}\right)$ were expressed as logarithmic response ratios (Lajeunesse 2015). For cercarial activity, only the 0-24 h interval was re-considered, linking this period to the infectivity experiment, in which mussels were incubated for $24 \mathrm{~h}$. Effects were considered significant when the confidence interval (CI) bar was not overlapping zero. Effect sizes (in percentages) of the different life cycle steps were calculated applying the inverse of the log mean ratio for (i), all temperature levels were pooled, and for (ii), all salinity levels were pooled.

\section{Results}

\section{Exp. I cercarial emergence}

For cercarial emergence, model selection through AIC revealed four top models having $\Delta$ AICs of $\leq 2.1$, with models including temperature or salinity and time, or an interaction between both (ESM Table S1). However, the model including only time as fixed factor described the data best (ESM Table S2). Cercariae output significantly decreased by $31 \%$ from the first to the second incubation in all treatments [GLMM, estimate value $(e v)=-0.78, z=-2.65, P=0.007$, ESM Table S2], and by $49 \%$ from the first to the third incubation (GLMM, $e v=-1.26, z=-3.92, P<0.0001$, ESM
Table S2). However, this happened with clearly variable patterns among treatments. The strongest decrease of cercarial release over time was observed at salinity 13 , while at salinity 19 , it remained fairly constant throughout the 2 weeks (Fig. 2). At $13-19{ }^{\circ} \mathrm{C}$ only, the $50 \%$ of the periwinkles shed cercariae, compared to $70-80 \%$ as observed in the other treatments (ESM Fig. S3).

\section{Exp. Il cercarial activity and survival}

In the integrated $0-24 \mathrm{~h}$ and $0-45 \mathrm{~h}$, cercarial activity was significantly decreasing with salinity (ANOVA, $0-24 \mathrm{~h}$ : $F_{2,12}=0.10, P=0.001 ; 0-45$ h: $F_{2,12}=12.45, P=0.001$, Table 1). Cercarial activity over $24 \mathrm{~h}$ was $31 \%$ lower at salinity 16 than salinity 19 and $37 \%$ lower at salinity 13 than 19 (Tukey test 16-19: $P=0.004$; salinities $13-19: P=0.002$ ). Cercarial activity over $45 \mathrm{~h}$ was $36 \%$ lower at salinity 16 than salinity 19 and $42 \%$ lower at salinity 13 than salinity 19 (Fig. 3; Tukey test: 16-19: $P=0.003 ; 13-19: P=0.002$ ). Cercarial survival showed no significant effects in the integrated $0-24 \mathrm{~h}$ interval. Contrarily, temperature had a negative effect in the integrated $0-45 \mathrm{~h}$, with survival at $23{ }^{\circ} \mathrm{C}$ $19 \%$ lower than at $19^{\circ} \mathrm{C}$ (ANOVA, $F_{1,12}=32.12, P=0.001$, Table 1).

\section{Exp. III cercarial infectivity}

Model selection indicated the model which only included salinity to be the best model (ESM Table S3). Infectivity significantly decreased with decreasing salinity. At salinity 16 , the proportion of cercariae successfully infecting

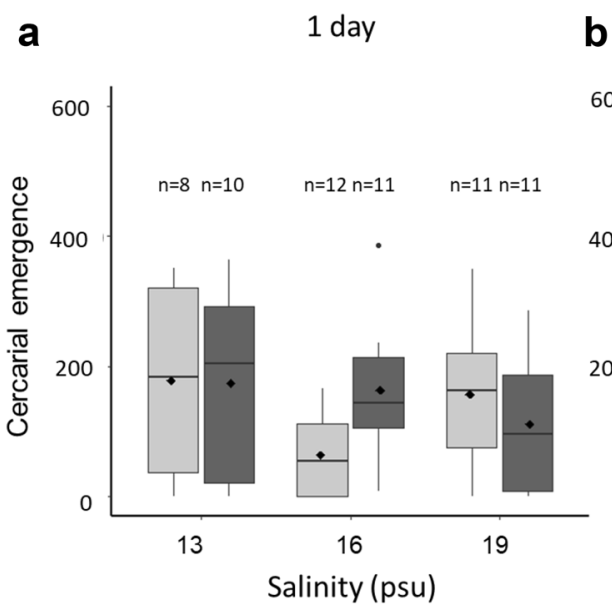

Fig. 2 Effects of temperature, salinity, and time on Himasthla elongata cercarial emergence during $8 \mathrm{~h}$ from Littorina littorea at three measurement points: a 1 day after acclimation, b 1 week after acclimation, and c 2 weeks after acclimation week in 19 and $23{ }^{\circ} \mathrm{C}$ seawater conditions at salinities of 13, 16, and 19. Each $n$ indicates the number of periwinkles shedding cercariae in each treatment. The
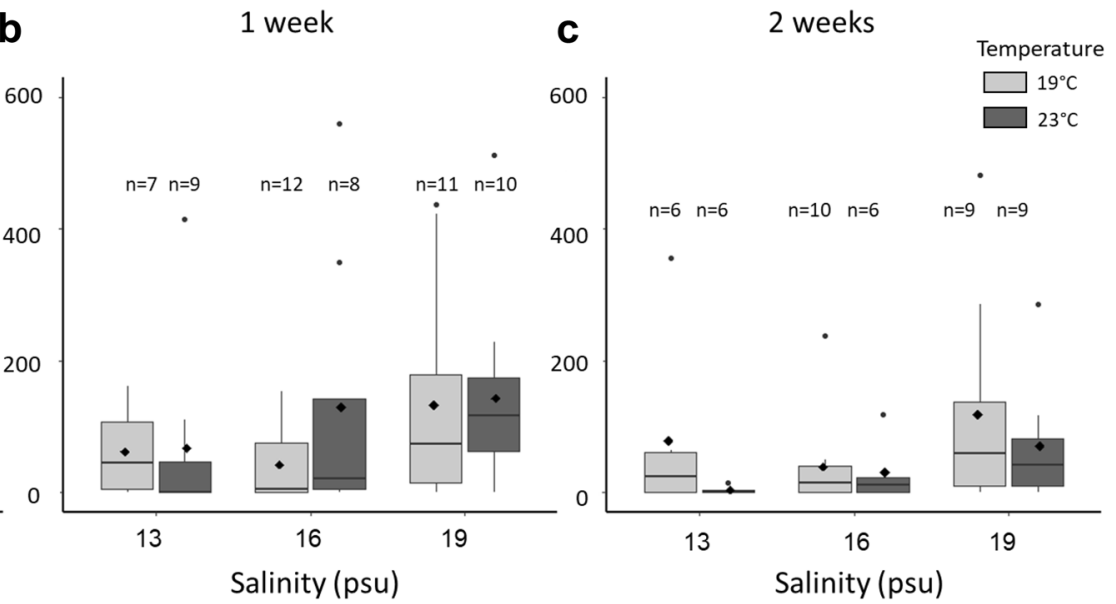

boxes represent the 75 (upper) and 25 (lower) percentile, the whiskers denote the lowest and the highest value, the black lines within the boxes the medians, the black diamond-shaped dots identify the means, and the black dots the outliers. Periwinkles that did not shed any cercariae in all the three incubations were excluded from the analysis and the plots 
Table 1 Results of a two-way ANOVA testing for the single and interactive effects of temperature $\left(19\right.$ and $\left.23^{\circ} \mathrm{C}\right)$ and salinity $(13,16$, and 19) on the integrated $24 \mathrm{~h}$ and $45 \mathrm{~h}$ activity and survival of Himasthla elongata cercariae

\begin{tabular}{|c|c|c|c|c|c|c|}
\hline Experiment & & Treatments & Df & MS & $F$ value & $P$ Value \\
\hline \multirow[t]{6}{*}{ Motility } & \multirow[t]{3}{*}{ Integrated $24 \mathrm{~h}$} & Temperature & 1 & 2.03 & 0.429 & 0.525 \\
\hline & & Salinity & 2 & 57.05 & 12.035 & $0.0013^{* *}$ \\
\hline & & Temperature $\times$ salinity & 2 & 10.95 & 2.309 & 0.142 \\
\hline & \multirow[t]{3}{*}{ Integrated $45 \mathrm{~h}$} & Temperature & 1 & 7.51 & 0.775 & 0.396 \\
\hline & & Salinity & 2 & 120.77 & 12.459 & $0.0011^{* *}$ \\
\hline & & Temperature $\times$ salinity & 2 & 20.77 & 2.143 & 0.160 \\
\hline \multirow[t]{6}{*}{ Survival } & \multirow[t]{3}{*}{ Integrated $24 \mathrm{~h}$} & Temperature & 1 & 1.43 & 1.812 & 0.203 \\
\hline & & Salinity & 2 & 0.08 & 0.101 & 0.905 \\
\hline & & Temperature $\times$ salinity & 2 & 1.00 & 1.268 & 0.316 \\
\hline & \multirow[t]{3}{*}{ Integrated $45 \mathrm{~h}$} & Temperature & 1 & 227.06 & 32.128 & $0.0001^{* * * *}$ \\
\hline & & Salinity & 2 & 1.54 & 0.218 & 0.807 \\
\hline & & Temperature $\times$ salinity & 2 & 11.63 & 1.645 & 0.234 \\
\hline
\end{tabular}

The “**"symbol indicates $P$ values $<0.01$ and “***”indicates $P$ values $<0.001$.

Bold text indicates significant $P$ values a

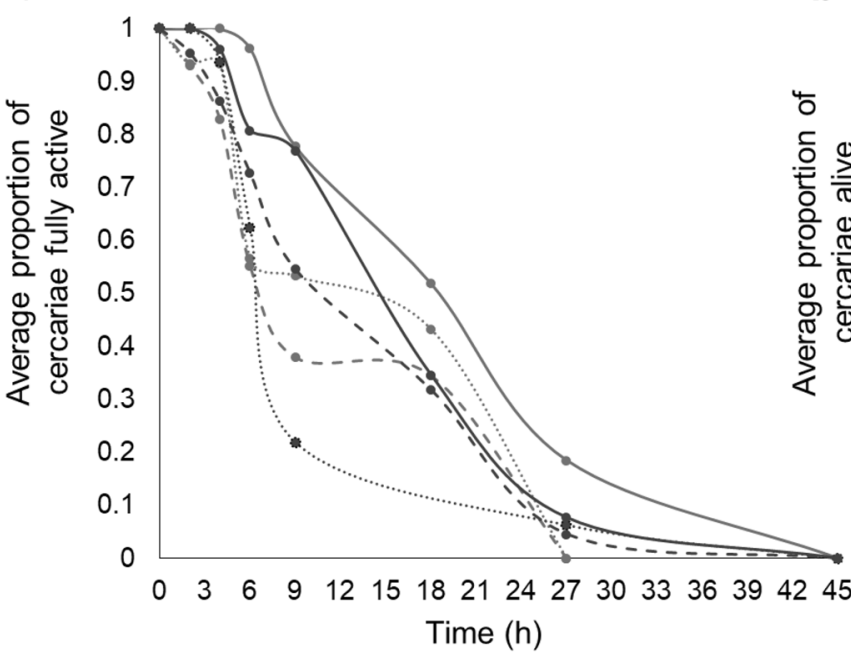

b

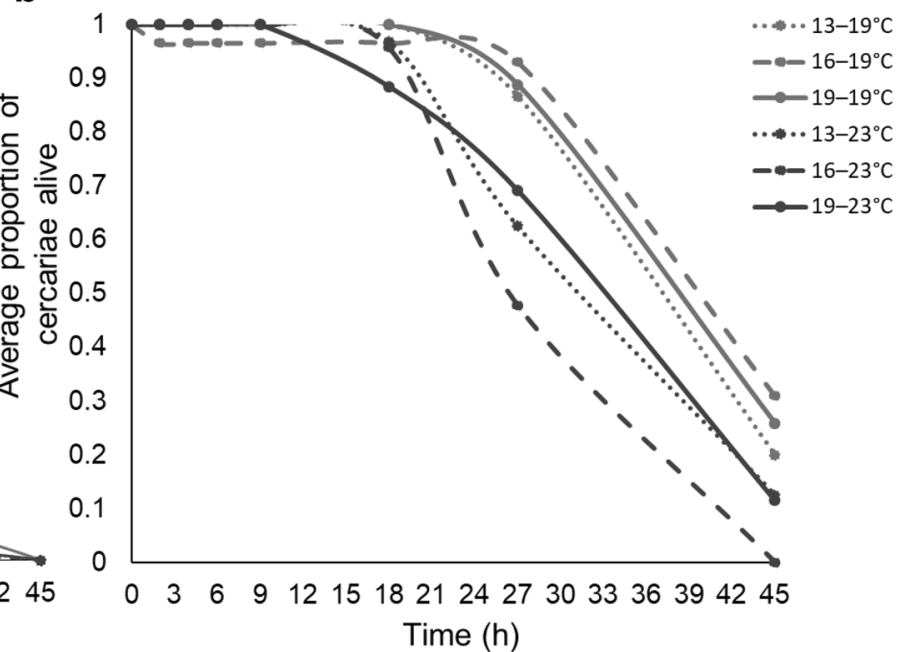

Fig. 3 Proportion of Himasthla elongata cercariae considered as a fully active (i.e., constantly swirling around; and b alive over 2, 4, 6, 9, 18, 27 , and $45 \mathrm{~h}$ post-release in 19 and $23^{\circ} \mathrm{C}$ seawater conditions at salinities of 13,16 , and 19

mussels was $33 \%$ lower than at salinity 19 (GLMM, $e v=0.46, z=2.03, P=0.041$, ESM Table S4), and at salinity 13 , this trait was $47 \%$ lower than at salinity 19 (GLMM, $e v=0.65, z=2.97, P=0.002$, Fig. 4, ESM Table S4). Models including temperature as an additional additive or interactive factor, even if not significant, also received substantial support from the data $(\triangle \mathrm{AIC} \leq 2 ; \mathrm{ESM}$ Table $\mathrm{S} 3)$. While at salinity 19 , infectivity was $21 \%$ higher at $23{ }^{\circ} \mathrm{C}$ compared to $19^{\circ} \mathrm{C}$, it was the opposite at salinity 16 (at $23{ }^{\circ} \mathrm{C}$ infectivity $44 \%$ lower than $19{ }^{\circ} \mathrm{C}$ ) (Fig. 4). Only very few cercariae were shed from periwinkles at the $13-23{ }^{\circ} \mathrm{C}$ treatment. Therefore, infection success could not be tested for $13-23{ }^{\circ} \mathrm{C}$.

\section{Exp. IV susceptibility of mussels}

Model selection identified the model including only salinity as the best model (ESM Table S5). The proportion of cercariae infecting acclimatised mussels decreased significantly with salinity. At salinity 16, the proportion was $19 \%$ lower than salinity 19 (GLMM, $e v=0.32, z=1.59, P=0.110$, ESM Table S6), and at salinity 13 , it was $43 \%$ significantly lower than salinity 19 (GLMM, $e v=0.61, z=3.03, P=0.002$, ESM Table S6). The model including temperature and salinity also explained the data reasonably well ( $\triangle$ AIC 1.85 , ESM 


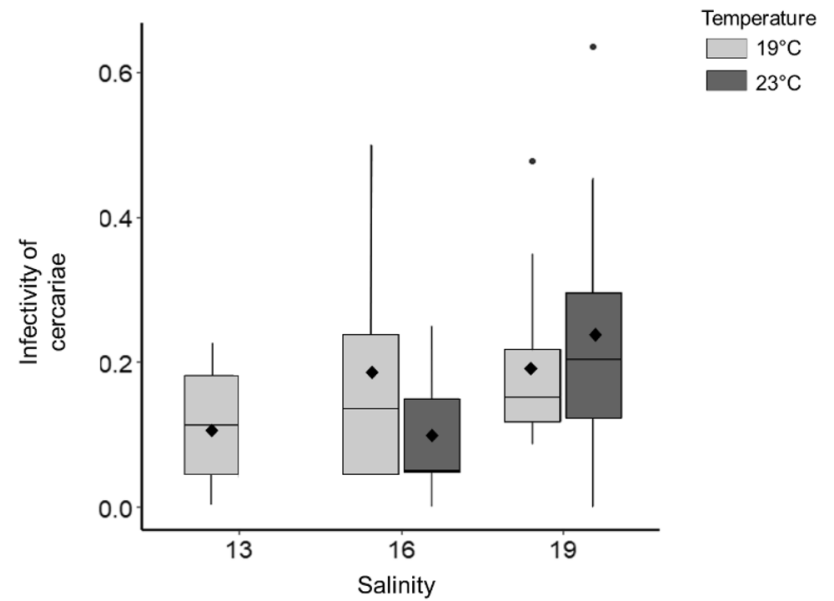

Fig. 4 Proportion of acclimated cercariae successfully infecting nonacclimated Mytilus edulis ( $n=12$ for each treatment, apart from 16 to $23{ }^{\circ} \mathrm{C}$, where $n=5$ ) following a $24 \mathrm{~h}$ incubation in 19 and $23{ }^{\circ} \mathrm{C}$ seawater conditions at salinities of 13,16 , and 19 . The $13-23{ }^{\circ} \mathrm{C}$ treatment was excluded from the experimental analyses due to the very low number of cercariae shed from the snails acclimatised to this respective treatment. The boxes represent the 75 (upper) and 25 (lower) percentile, the whiskers denote the lowest and the highest value, the black lines in the boxes are the medians, the black diamond-shaped dots identify the means, and the black dots the outliers

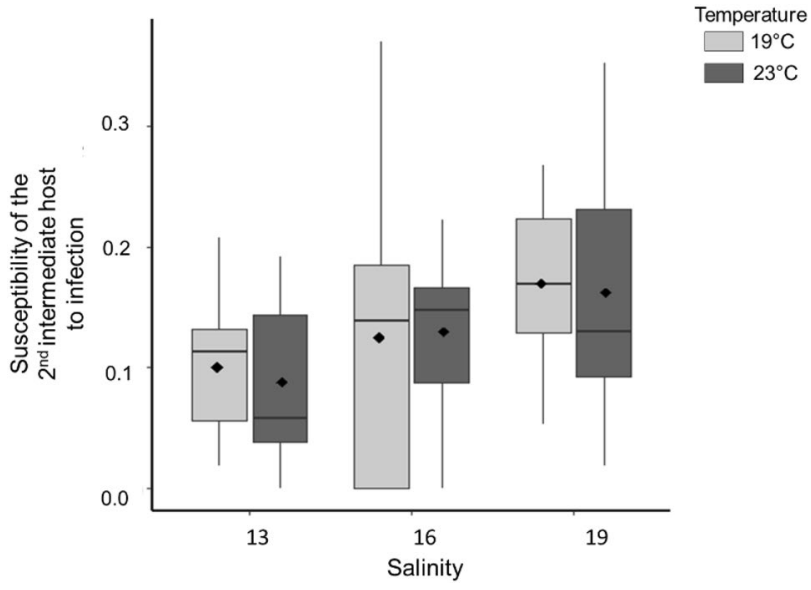

Fig. 5 Proportion of non-acclimated cercariae infecting acclimated Mytilus edulis ( $n=12$ for each treatment) following a $24 \mathrm{~h}$ incubation in 19 and $23{ }^{\circ} \mathrm{C}$ seawater conditions at salinities of 13,16 , and 19. The boxes represent the 75 (upper) and 25 (lower) percentile, the whiskers denote the lowest and the highest value, the black lines within the boxes the medians, and black diamond-shaped dots identify instead of the means

Table S5). The patterns in the plot (Fig. 5) show a similar susceptibility between hosts at salinity 16 and at salinity 19 at 19 and $23{ }^{\circ} \mathrm{C}$, but lower susceptibility at $23{ }^{\circ} \mathrm{C}$ than at $19^{\circ} \mathrm{C}$ at salinity 13 .

\section{Future versus present conditions in our study system}

After pooling the temperature levels, log response ratios showed a significant decrease of cercarial emergence (to $54 \%$ ), cercarial activity (to $80 \%$ ), cercarial infectivity (to $70 \%$ ), and second intermediate host susceptibility (75\%) in an extreme future freshening scenario from salinity 19 (ambient condition) to 13 (future condition; Fig. 6a). Contrarily, after pooling the salinity levels, and comparing future global warming $\left(23^{\circ} \mathrm{C}\right)$ with today's temperatures $\left(19^{\circ} \mathrm{C}\right)$, only cercarial emergence and long-term survival (45 h) decreased significantly, to $70 \%$ and $90 \%$, respectively (i.e., confidence intervals not overlapping zero; Fig. 6b).

\section{Discussion}

To date, studies of environmental effects on the free-living stages of parasites in the Baltic Sea are rare, apart from experiments by Möller (1978) about the combined influence of temperature and salinity on the survival of fish parasites. In this study, we assessed the possible impact of warming and freshening on specific transmission stages from the first to the second intermediate host of a common marine trematode of the western Baltic Sea. Salinity had the strongest effects on most transmission steps: cercarial emergence, activity, infectivity, and second intermediate host susceptibility all decreased with decreasing salinity. In contrast, only cercarial emergence and survival were affected by temperature, both decreasing with the warming scenario. Interaction effects between salinity and temperature were weak or absent.

\section{Cercarial emergence}

Cercarial emergence decreased over the experimental duration; accordingly, time was the factor contributing to the model that fitted the data best. However, over the entire experimental period, cercarial emergence significantly decreased to $54 \%$ with sea water freshening (salinity 13 ) and to $70 \%$ with warming compared to the ambient condition (salinity 19; Fig. 6). Both observations are in line with the previous studies which showed a positive relationship between cercarial emergence and increase in salinity (Sindermann and Farrin 1962; Lei and Poulin 2011; Studer and Poulin 2012) as well as increase in temperature (Mouritsen 2002; Studer et al. 2010). Cercarial emergence typically increases with temperatures until an optimum, usually determined by the host tolerance and by acclimation to changed environmental conditions (Erasmus 1972; Ataev 1991; Morley and Lewis 2013). The number of cercariae released during our measurement 1 (after 7 days of acclimation) 

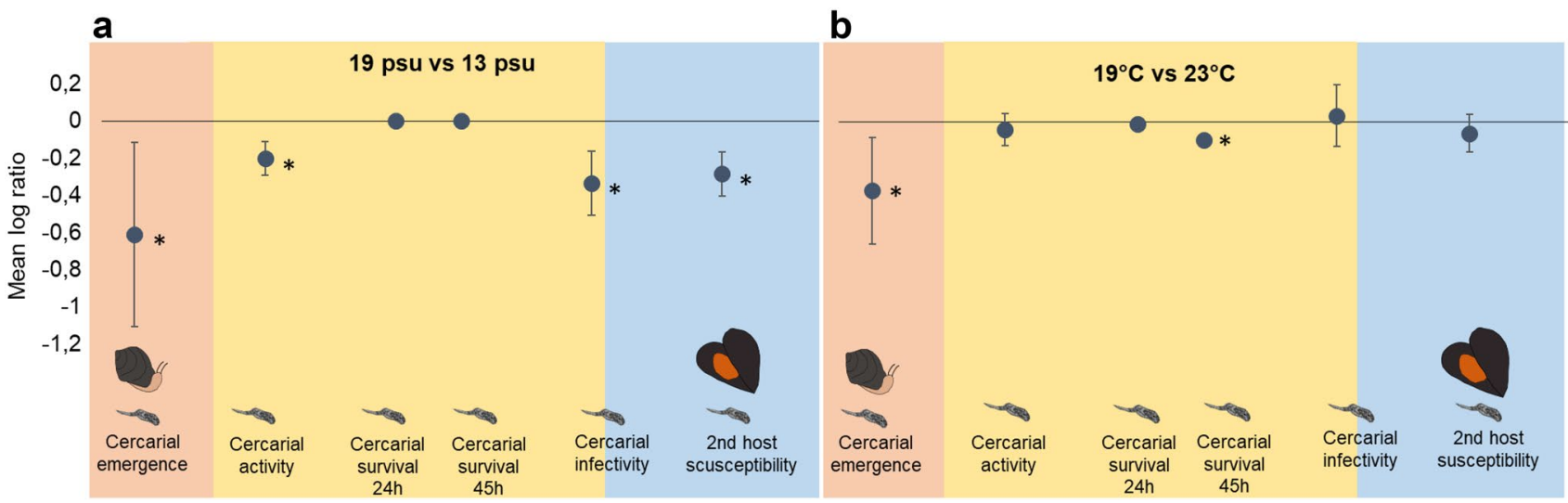

Fig. 6 Logarithmic response ratios for: cercarial emergence, cercarial activity after $24 \mathrm{~h}$, cercarial survival after 24 and $45 \mathrm{~h}$, cercarial infectivity, and mussel (second intermediate host) susceptibility. a Effects of desalination ( $\log$ [(trait at 13)/ (trait at 19)]) with data from the two temperature treatments pooled, and $\mathbf{b}$ effects of warming (log $\left[\left(\right.\right.$ trait at $\left.19{ }^{\circ} \mathrm{C}\right) /\left(\right.$ trait at $\left.\left.23{ }^{\circ} \mathrm{C}\right)\right]$ ) with data from the three salinity lev- els pooled. Error bars represent $95 \%$ confidence intervals. Significant effects are indicated by ' $*$ '. Different colours represent the different effects on: (i) cercarial shedding from periwinkles (red), (ii) cercarial survival and infectivity (yellow), and (iii) susceptibility of mussel to infections (blue)

better with increasing salinity. The reason for the decreased cercarial activity at lower salinities is probably attributable to osmotic stress. Body fluids of periwinkles are known to be isosmotic down to 15 , below which the fluids become hyperosmotic (Todd 1964; Rumsey 1973). Cercariae released from hosts under such low-salinity conditions might been subjected to an osmotic shock after emergence (Lauckner 1984a, b). Supporting this, in coastal waters with salinity below $15, H$. elongata infections were registered only in periwinkles at the bottom of shallow waters (Lauckner 1984a, b). Stratification of the water column in the Baltic Sea often leads to the deeper water layer being higher in salinity and lower in temperature (Liblik and Lips 2019). In contrast to activity, cercarial survival was negatively affected by temperature only. Over $45 \mathrm{~h}$, survival decreased significantly by $10 \%$ at the higher temperature $\left(23^{\circ} \mathrm{C}\right)($ Fig. 6) compared to ambient $\left(19^{\circ} \mathrm{C}\right)$. Similar results have been reported previously (Mouritsen 2002; Koprivnikar et al. 2010), possibly resulting from higher temperatures accelerating the metabolism of cercariae leading to a faster depletion of their finite energy reserves (Pechenik and Fried 1995). This in turn might have direct consequences for their transmission success in a future warmed ocean.

\section{Cercarial infectivity and susceptibility of mussels}

Freshening had a negative effect on cercarial infectivity which decreased significantly with desalination to $70 \%$ compared to ambient condition (salinity 19; Fig. 6). Freshening has been shown previously to reduce cercarial infectivity, possibly because of the vulnerability of the free-living stages of marine trematodes to low salinity (Pietrock and Marcogliese 2003). Furthermore, as shown by Stunkard and itrema (Microphallidae) and (Koprivnikar et al. 201 Studer and Poulin 2012), generally showing cercariae to fare 
Shaw (1931), osmotic stress could provoke slower cyst formation during infection. A previous study by Riisgård et al. (2013) found no differences in filtration rate of blue mussels collected at salinity 17.5 and exposed for 2 weeks to a range of salinities (10-30). Hence, the reduced infectivity with freshening could be merely attributed to the acclimatised cercariae. The susceptibility of the mussel host was also negatively affected by seawater freshening to $75 \%$ of the ambient condition (Fig. 6). Accounting that filtration rate at lower salinity is not significantly reduced during 1 week of acclimation, other reasons narrowed to susceptibility should be attributed, which remain unknown. However, the difference of $5 \%$ between decreased infectivity (70\%) and susceptibility $(75 \%)$ with desalination leads to argue that acclimation mattered. To exclude any effect of changes in filtration on susceptibility, a longer acclimation period to the mussels would be required. Moreover, further experiments investigating physiological responses of mussels while infected by cercariae could also be useful for a better understanding of mussel susceptibility. Interestingly, no significant effects of temperature or interaction between temperature and salinity were observed for both cercarial infectivity and mussel susceptibility. This suggests a limited importance of temperature for cercarial infectivity and mussel susceptibility in this parasite-host system. However, it may be that stronger warming scenario $\left(>4{ }^{\circ} \mathrm{C}\right)$ or extreme future conditions during heatwaves could have resulted in stronger temperature responses. For example, Pansch et al. (2018) found M. edulis to tolerate temperature peaks better than other bivalve species. Seemingly, only at very high temperatures, the mussel immune system may become compromised leading to an increase of cercarial infection.

\section{Expected shifts in parasitism in response to desalination and warming}

In general, our experiments suggest that future desalination scenarios for the Baltic Sea may lead to lower cercarial transmission rates, and therefore lower infection levels in mussel hosts, with salinity having more profound effects than temperature. Based on the combined effects of decreasing cercarial emergence (reduced to $54 \%$ with freshening), cercarial activity (reduced to $80 \%$ with freshening), cercarial survival (reduced to $90 \%$ with warming over $45 \mathrm{~h}$ ), and mussel susceptibility (reduced to $75 \%$ with freshening), future climate scenarios could lead to a decrease in infection levels of $H$. elongata in mussels to around $30 \%(0.54 \times 0.8 \times 0.9 \times 0.75)$. Such lower infection levels in mussels with decreasing salinity are also supported from field data along the Western Baltic coast, in which prevalence of trematodes in M. edulis at salinities below 15 was reduced by $80 \%$ relatively to higher salinities (Bommarito et al. unpublished.). These predictions suggest that global change may not always lead to elevated levels of parasitism as predicted by some studies (Poulin 2006; Studer et al. 2010), which could be beneficial for the host populations. It must be emphasized that the direction of global change effects is probably not universal, but conditional on the respective parasite-host systems, and the particular environmental context. Steep salinity gradients can be found in many coastal seas worldwide, for example, areas in which glacier meltwaters release freshwater into the sea, or the many estuaries resulting from larger river runoffs. Therefore, the data collected on the host-parasite system in the present study are not relevant to the Baltic Sea only, but might be applied to other host-parasite systems. Furthermore, $H$. elongata is distributed worldwide, and testing whether the response of this species to changes in temperature or salinity differs with latitude would be beneficial. Our experiments only investigated the transmission from the first to the second intermediate host. Further experiments on other life cycle stages of $H$. elongata, such as on eggs or miracidial stages, are needed to fully understand the climate change effects on this entire host-parasite system, and whether our findings can be extended to other marine trematode species. Acidification could be also included, especially in experiments involving molluscs as intermediate hosts. In addition, parasite transmission and host infection levels under climate change will also be affected by other factors such as the density of the intermediate hosts, the presence of the final hosts, as well as other environmental factors. All of these are important to consider in developing a full picture of the climate change effects on host-parasite interactions.

\section{Ethical statement}

This study was funded by the Ca' Foscari University of Venice, Italy, and GEOMAR Helmholtz Centre for Ocean Research in Kiel, Germany, with no conflict of interest. All applicable international, national, and/or institutional guidelines for sampling, care, and experimental use of organisms for the study have been followed.

Acknowledgements Open Access funding provided by Projekt DEAL. We would like to thank Tim Staufenberger from the Kieler Meeresfarm for kindly providing the uninfected mussels used for the experiment and Ola Mohamed Nour for the help in the laboratory. CB and MW acknowledge financial support by BMBF (Germany Ministry of Research and Education) through the project BIOMOD (\#03FO821A). $\mathrm{CB}$ acknowledges financial support by the Ca' Foscari University of Venice, Italy and GEOMAR Helmholtz Centre for Ocean Research in Kiel, Germany.

Open Access This article is licensed under a Creative Commons Attribution 4.0 International License, which permits use, sharing, adaptation, distribution and reproduction in any medium or format, as long as you give appropriate credit to the original author(s) and the source, provide a link to the Creative Commons licence, and indicate if changes 
were made. The images or other third party material in this article are included in the article's Creative Commons licence, unless indicated otherwise in a credit line to the material. If material is not included in the article's Creative Commons licence and your intended use is not permitted by statutory regulation or exceeds the permitted use, you will need to obtain permission directly from the copyright holder. To view a copy of this licence, visit http://creativecommons.org/licenses/by/4.0/.

\section{References}

Al Janabi B, Wahl M, Karsten U, Graiff U, Kruse I (2019) Sensitivities to global change drivers may correlate positively or negatively in a foundational marina alga. Sci Rep. https://doi.org/10.1038/ s41598-019-51099-8

Ataev GL (1991) Development of rediae and cercariae of Philophthalmus rhionica (Trematoda) in starved molluscan hosts. Parazitologiya 25(5):456-461

Bonsdorff E (2006) Zoobenthic diversity-gradients in the Baltic Sea: continuous post-glacial succession in a stressed ecosystem. J Exp Mar Biol Ecol 333:383-391

de Montaudouin X, Blanchet H, Desclaux-Marchand C, Lavesque N, Bachelet G (2016) Cockle infection by Himasthla quissetensis - I. From cercariae emergence to metacercariae infection. J Sea Res 113:99-107

Erasmus DA (1972) The biology of trematodes. The University Press, Belfast

Franz M, Lieberum C, Bock G, Karez R (2019) Environmental parameters of shallow water habitats in the SW Baltic Sea. Earth Syst Sci Data 11:947-957

Greve T (1997) Interaktioner mellem den marine parasit Himasthla elongata og dennes anden mellemvert den almindelige hjertemusling (Cerastoderma edule) Master thesis. University of Aarhus, Department of Marine Ecology

IPCC (2019) IPCC Special Report on the Ocean and Cryosphere in a Changing Climate. In: Pörtner HO, Roberts DC, Masson-Delmotte V, Zhai P, Tignor P, Poloczanska E, Mintenbeck K, Alegría A, Nicolai M, Okem A, Petzold J, Rama B, Weyer NM (eds.) In press.

Jasper C, Møller LF, Kiørboe T (2011) Salinity gradient of the baltic sea limits the reproduction and population expansion of the newly invaded comb jelly Mnemiopsis leidy. PLoS ONE 6(8):e24065. https://doi.org/10.1371/journal.pone.0024065

Johnson PR, Kotta J, Andersson HC, Herkül K, Virtanen E, Nystr Sandman A, Johannesson (2018) High climate velocity and population fragmentation may constrain climate-driven range shift of the key habitat former Fucus vesiculosus. Divers Distrib 24(7):892-905

Koprivnikar J, Poulin R (2009) Effects of temperature, salinity, and water level on the emergence of marine cercariae. J Parasitol Res 105(4):957-965

Koprivnikar J, Lim D, Fu C, Brack SHM (2010) Effects of temperature, salinity, and $\mathrm{pH}$ on the survival and activity of marine cercariae. J Parasitol Res 106(5):1167-1177

Lajeunesse MJ (2015) Bias and correction for the log response ratio in ecological meta-analysis. Ecology 96(8):2056-2063

Lauckner G (1984a) Brackish-water submergence of the common periwinkle, Littorina littorea, and its digenean parasites in the Baltic Sea and in the Kattegat. Helgoländer Meeresunters. 37:177-184

Lauckner G (1984b) Impact of trematode parasitism on the fauna of a North Sea tidal flat. Helgoländer Meeresunters 37:185-199

Laverty C, Brenner D, McIlwaine C, Lennon JJ, Dick JTA, Lucy FE, Christian KA (2017) Temperature rise and parasitic infection interact to increase the impact of an invasive species. Int J Parasitol 47:291-296

Lei F, Poulin R (2011) Effects of salinity on multiplication and transmission of an intertidal trematode parasite. Mar Biol 158(5):995-1003

Leiva NV, Manríquez PH, Aguilera VM, González MT (2019) Temperature and $\mathrm{pCO} 2$ jointly affect the emergence and survival of cercariae from a snail host: implications for future parasitic infections in the Humboldt Current system. Int J Parasitol 49:49-61

Liblik T, Lips U (2019) Stratification has strengthened in the baltic sea - an analysis of 35 years of observational data. Front Earth Sci 7:1-15

Marcogliese DJ (2008) The impact of climate change on the parasites and infectious diseases of aquatic animals. Rev Sci Tech 27(2):467-484

Marcogliese DJ (2016) The distribution and abundance of parasites in aquatic ecosystems in a changing climate: more than just temperature. Int Comp Biology 56(4):611-619

McCarthy AM (1999) The influence of temperature on the survival and infectivity of the cercariae of Echinoparyphium recurvatum (Digenea: Echinostomatidae). Parasitology 118:383-388

Möller H (1978) The effects of salinity and temperature on the development and survival of fish parasites. J Fish Biol 12(4):311-323

Morley NJ (2011) Thermodynamics of cercarial survival and metabolism in a changing climate. Parasitology 138:1442-1452

Morley NJ, Lewis JW (2013) Thermodynamics of cercarial development and emergence in trematodes. Parasitology 140(10):1211-1224

Mouritsen KN (2002) The parasite-induced surfacing behaviour in the cockle Austrovenus stutchburyi: a test of an alternative hypothesis and identification of potential mechanisms. Parasitology 124(5):521-528

Mouritsen KN, Poulin R (2009) Parasitism as a determinant of community structure in intertidal flat. Mar Biol 157:201-213

Müller JD, Schneider B, Rehder G (2016) Long-term alkalinity trends in the Baltic Sea and their implications for CO2-induced acidification. Limn Oceanography 61(6):1984-2002

Nachev M, Sures B (2015) Environmental parasitology: Parasites as accumulation bioindicators in the marine environment. J Sea Res 113:45-50

Nakagawa S, Schielzeth H (2013) A general and simple method for obtaining $\mathrm{R}^{\wedge} 2$ from generalized linear mixed-effects models. Methods Ecol Evol 4:133-142

Ojaveer H, Jaanus A, MacKenzie BR, Martin G, Olenin S, Radziejewska T, Telesh I, Zettler M, Zaiko A (2010) Status of biodiversity in the Baltic Sea. PLoS ONE 5(9):e12467

Pansch C, Scotti M, Barboza F, Al-Janabi B, Brakel J, Briski E, Bucholz B, Franz F, Ito M, Paiva F, Saha M, Sawall Y, Weinberger F, Wahl M (2018) Heat waves and their significance for a temperate benthic community : A near-natural experimental approach. Glob Change Bio 24(9):4357-4367

Pechenik J, Fried B (1995) Effect of temperature on survival and infectivity of Echinostoma trivolvis cercariae: a test of the energy limitation hypothesis. Parasitology 11:373-378

Pietrock M, Marcogliese DJ (2003) Free-living endohelminth stages: at the mercy of environmental conditions. Trends Parasitol 19(7):293-299

Poulin R (2006) Global warming and temperature-mediated increases in cercarial emergence in trematode parasites. Parasitology 132:143-151

Poulin R, Mouritsen KN (2006) Climate change, parasitism and the structure of intertidal ecosystems. J Helminthol 80:183-191

R Core Team (2018) R: a language and environment for statistical computing. R Foundation for Statistical Computing, Vienna, Austria

Reusch TB, Dierking J, Andersson HC, Bonsdorff E, Carstensen J, Casini M, Czajkowski M, Hasler B, Hinsby K, Hyytiäinen K, 
Johannesson K, Jomaa S, Jormalainen V, Kuosa H, Kurland S, Laikre L, MacKenzie BR, Margonski P, Melzner F, Oesterwind D, Ojaveer H, Refsgaard JC, Sandström A, Schwarz G, Tonderski K, Winder M, Zandersen M (2018) The Baltic Sea as a time machine for the future coastal ocean. Sci Adv 4(5):eaar8195

Riisgård HU, Lüskow F, Pleissner D, Lundigreen K, López MAP (2013) Effect of salinity on filtration rates of mussels Mytilus edulis with special emphasis on dwarfed mussels from the lowsaline Central Baltic Sea. Helgol Mar Res 63:591-598

Rosenberg R, Rosenberg K (1972) Salinity tolerance in three Scandinavian populations of Littorina Littorea (L) (Gastropoda). Ophelia 10(2):129-139

Rumsey TJ (1973) Some aspects of osmotic and ionic regulation in Littorina littorea (L.) (Gastropoda, Prosobranchia). Comp Biochem Physiol 45(4):327-344

Sindermann CJ, Farrin AE (1962) Ecological studies of Cryptocotyle lingua (Trematoda: Heterophyidae) whose larvae cause 'pigment spots' of marine fish. Ecology 43:69-75

Studer A, Poulin R (2012) Effects of salinity on an intertidal hostparasite system: Is the parasite more sensitive than its host? J Exp Mar Biol Ecol 412:110-116

Studer A, Poulin R (2013) Cercarial survival in an intertidal trematode: A multifactorial experiment with temperature, salinity and ultraviolet radiation. J Parasitol Res 112(1):243-249

Studer A, Thieltges D, Poulin R (2010) Parasites and global warming: net effects of temperature on an intertidal host-parasite system. Mar Ecol Prog Ser 415:11-22

Stunkard H, Shaw C (1931) The effect of dilution of sea water on the activity and longevity of certain marine cercariae, with descriptions of two new species. Biol Bull 61:242-271

Sures B (2008) Host-parasite interaction in polluted environments. J Fish Biol 73:2133-2142
Sures B, Nachev M, Pahl M, Grabner D, Selbach C (2017) Parasites as drivers of key processes in aquatic ecosystems: Facts and future directions. J Exp Parasitol 180:141-147

Thieltges DW, Rick J (2006) Effect of temperature on emergence, survival and infectivity of cercariae of the marine trematode Renicola roscovita (Digenea: Renicolidae). Dis Aquat Organ 73(1):63-68

Todd ME (1964) Osmotic balance in Littorina littorea, L. littoralis and L. saxatilis (Littorinidae). Physiol Zool 37:33-44

Wegeberg A (1998) Digene trematoders (Echlnostomatidae) Infektionsøkologi og effekt pâ Cerastoderma edule. Master thesis. Depet of Marine Ecology, Univ. of Aarhus.

Vidal-Martìnez VM, Wunderlich AC (2017) Parasites as bioindicators of environmental degradation in Latin America: A meta-analysis. J Helminth 91:165-173

Vuorinen I, Hänninen J, Rajasilta M, Laine P, Eklund J, MontesinoPouzols F, Corona F, Junker K, Meier MHE, Dippner JW (2015) Scenario simulations of future salinity and ecological consequences in the Baltic Sea and adjacent North Sea areas-implications for environmental monitoring. Ecol Ind 50:196-205

Wood CL, Byers JE, Cottingham KL, Altman I, Donahue MJ, Blakeslee AMH (2007) Parasites alter community structure. Proc Natl Acad Sci 194:9335-9339

Zander CD (1998) Ecology of Host Parasite Baltic Sea. Naturwissenschaften Rev Art 85:426-436

Publisher's Note Springer Nature remains neutral with regard to jurisdictional claims in published maps and institutional affiliations. 